\title{
Comparison of Post Intubation Complications of Endotracheal Tube and Laryngeal Mask Airway in Pediatrics
}

\author{
Kamran Mottaghi, ${ }^{1}$ Ali Eftekharian, ${ }^{2}$ Alireza Salimi, ${ }^{1,}$ Anis Pouyanfar, ${ }^{1}$ Alireza Jahangiri, ${ }^{1}$ Masoud \\ Nashibi, ${ }^{1}$ Seyed Amir Mohajerani, ${ }^{1}$ and Saeed Malek ${ }^{1}$ \\ ${ }^{1}$ Department of Anesthesiology, Shahid Beheshti University of Medical Sciences, Tehran, Iran \\ ${ }^{2}$ Department of Oto-Rhinolaryngology, Shahid Beheshti University of Medical Sciences, Tehran, Iran \\ "Corresponding author: Alireza Salimi, Department of Anesthesiology, Shahid Beheshti University of Medical Sciences, Tehran, Iran. E-mail: arsalimi@sbmu.ac.ir
}

Received 2016 December 25; Revised 2017 January 17; Accepted 2017 January 18.

\begin{abstract}
Background: Postoperative sore throat, cough, nausea, apnea, and laryngospasm are common complications of intubation by endotracheal tube (ETT) in pediatrics. The laryngeal mask airway (LMA) is a supraglottic device used as an alternative equipment for ETT in order to decrease the complications.

Objectives: To compare the incidence of postoperative sore throat after LMA with ETT in pediatrics.

Methods: Seventy-six patients between the ages of 2-12 with ASA class I-II who underwent cochlear implant surgery were enrolled and randomly divided into 2 groups including ETT or LMA for airway management. The incidence of complications including sore throat, apnea, vomiting, laryngospasm, post operative cough, intra, and post operative arrhythmia and the influence of these equipment's on $\mathrm{O}_{2}$ saturation, end tidal $\mathrm{CO}_{2}$, airway pressure, and hemodynamic changes during operation were compared. Wong-Baker facial grimace scale was used to evaluate the severity of pain.

Results: The rate of postoperative sore throat and laryngospasm in the ETT group was significantly higher than the LMA group $(\mathrm{P}=$ $0.002,0.011$; respectively). Apnea and vomiting were not significantly different. Rate of postoperative cough, incidence of intra, and postoperative arrhythmia were not significantly different between the two groups. Mean arterial pressure, peak airway pressure, end tidal $\mathrm{CO}_{2}$, and oxygen saturation during operation, which was measured continuously, had no significant differences between the two groups.

Conclusions: LMA significantly decreases the rate of postoperative sore throat and laryngospasm in pediatrics. However, the rates of apnea, oxygen saturation, and nausea were similar in both groups. Application of LMA as an alternative to ETT is appropriate in pediatric patients.
\end{abstract}

Keywords: Laryngeal Mask Airway (LMA), Endotracheal Tube (ETT), Cochlear Implants, Sore Throat, Pediatric Patients

\section{Background}

Cochlear implant surgery is the mainstay treatment for pediatric patients with severe to profound sensory neural hearing loss. Candidates for this surgery are mostly 1-year-old children and older. Prosthetic devices used in the operation transform environmental sounds into electrical signals and sends to the auditory nerve $(1,2)$. Therefore, checking this nerve is a mandatory requirement during this surgery. On the other hand, since this procedure is a microscopic surgery, it is an extended and time-consuming procedure, therefore airway managing in these patients with an average age range of 2 to 12 years during anesthesia is of paramount importance.

Sore throat after surgery is a common complication in about $60 \%$ of patients after general anesthesia. Trauma during insertion of the tube, endotracheal tube size, type of cuff, manipulation of airway and surrounding tissues, lack of airway moisture, and high gas flow rate are its probable causes (3).

Using a tracheal tube is a standard method in airway management, however, the laryngeal mask airway is an appropriate alternative. To check the auditory nerve during cochlear implant surgery, the relaxants must not be used. This can be achieved by the use of laryngeal mask airway, as its insertion is easy and needs smaller doses of muscle relaxants for induction and maintenance $(4,5)$.

In this study, the laryngeal mask airway was used in comparison with the tracheal tube. The outcomes of both devices, including the sore throat as a primary outcome and hemodynamic status, oxygen saturation $\left(\mathrm{S}_{\mathrm{P}} \mathrm{O}_{2}\right)$, the amount of $\mathrm{CO}_{2}$ in exhaled air $\left(\mathrm{ETCO}_{2}\right)$ as secondary outcomes were compared. 


\section{Methods}

\subsection{Patient Selection}

In this study, 76 ASA I.II patients aged 2 - 12 years old were hospitalized in Loghman Hakim hospital for cochlear implant surgery and were studied after obtaining the informed written consent of their parents or legal guardians.

The eligible patients were randomly divided into 2 groups using a laryngeal mask airway or tracheal tube. The same commercial product (TUORen TM LMA Wellkang Ltd t / a wellkang Tech Consulting UK) was used for all patients in the laryngeal mask airway group. The appropriate size of the endotracheal tube was determined for the tracheal tube group with the formula (age $+16 / 4$ ). The same commercial product (Well Lead TM Well Lead Medical Co. Ltd China) was used for all the patients in this group.

\subsection{Method of Anesthesia}

Premedication and induction methods were the same in both groups; $2 \mu \mathrm{g} / \mathrm{kg}$ fentanyl within 5 minutes before the operation, $0.03 \mathrm{mg} / \mathrm{kg}$ midazolam and $4 \mathrm{cc} / \mathrm{kg}$ ringer were used as the premedication; $5 \mathrm{mg} / \mathrm{kg}$ thiopental, 0.5 $\mathrm{mg} / \mathrm{kg}$ atracurium, and $1 \mathrm{mg} / \mathrm{kg}$ lidocaine were used in the induction of anesthesia.

For the maintenance of anesthesia, $100 \mu \mathrm{g} / \mathrm{kg} / \mathrm{IV} / \mathrm{min}$ propofol and $0.1 \mu \mathrm{g} / \mathrm{kg} / \mathrm{IV} / \mathrm{min}$ remifentanil was used. Since the surgeon used nerve monitoring to avoid nerve damage, we did not use maintenance doses of neuromuscular blockers; at the end of surgery, remaining neuromuscular blockade was reversed using Neostigmin 0.05 $\mathrm{mg} / \mathrm{kg}$ and Atropin $0.02 \mathrm{mg} / \mathrm{kg}$. Ventilator was set to $6 \mathrm{cc} / \mathrm{kg}$ TV (Tidal Volume) with a respiratory rate of 14 . At the beginning of anesthesia, some parameters such as pulse rate (PR), blood pressure (BP), ET CO2 (end tidal $\mathrm{CO}_{2}$ ), oxygen saturation, and pressure of airway (PAW) were measured and their measurement was repeated every $15 \mathrm{~min}$ utes during anesthesia. Additionally, the desired parameters, including outcomes in both groups (the level of sore throat, nausea, and vomiting immediately after surgery and during 24 hours after surgery and the incidence of bronchospasm, laryngospasm, and apnea), the number of failures and the failure of each procedure, operation field bleeding, and $\mathrm{O}_{2}$ saturation after surgery were studied.

\subsection{Postoperative Pain Measurement}

In order to assess the pain level, patients were trained to evaluate their pain by the visual analog scale (VAS), using faces expressing the level of pain, before operation (Figure 1). This assessment was done in constant intervals after the operation. Furthermore, some questions were designed in the Likert scale to assess the patient's satisfaction with anesthetic management.

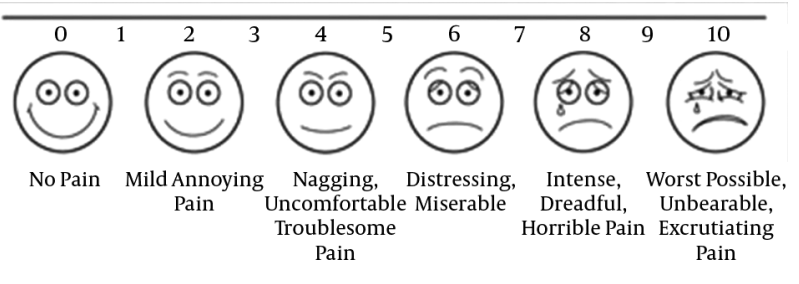

Figure 1. Visual Analog Scale

\subsection{Data Analysis}

The recorded data was analyzed using chi-square and $\mathrm{t}$ test analysis in SPSS 21 and $\mathrm{P}<0.05$ was considered as significant.

\section{Results}

In this study, the endotracheal tube (ETT) for 34 patients and laryngeal mask airway (LMA) for 42 patients were used to manage their airway. There was no significant difference in terms of demographic data and surgery duration between the 2 groups (Table 1 ).

Table 1. Demographic Characteristics of Patients and Surgery Duration $(\bar{X} \pm$ SD $)$

\begin{tabular}{lccc}
\hline Group & Age, $\mathbf{y}$ & Weight, $\mathbf{k g}$ & Duration, min \\
\hline ETT $(\mathbf{n}=\mathbf{3 4})$ & $5 \pm 3$ & $15 \pm 2$ & $150 \pm 30$ \\
$\operatorname{LMA}(\mathbf{n}=\mathbf{4 2})$ & $6 \pm 2$ & $16 \pm 1$ & $148 \pm 35$ \\
Sig & NS & NS & NS \\
\hline
\end{tabular}

Abbreviations: ETT, Endotracheal Tube; LMA, Laryngeal Mask Airway; NS, Not Statistically Significant.

Sore throat incidence in ETT(endotracheal tube) group was significantly higher than the LMA (laryngeal mask airway) group after operation (Table 2).

Table 2. Comparison of Sore Throat Incidence in Two Groups of LMA and ETT ${ }^{\mathrm{a}}$

\begin{tabular}{|c|c|c|c|}
\hline Group & ST+ & ST - & PValue \\
\hline ETT (34) & $12(35.5)$ & $22(64.5)$ & \multirow{2}{*}{0.002} \\
\hline LMA (42) & $2(4.8)$ & $40(95.2)$ & \\
\hline
\end{tabular}

There was no significant difference in terms of the studied parameters including arrhythmia, bleeding, oxygen desaturation, laryngospasm, apnea, and vomiting between the 2 groups of study (Tables $3-5$ ).

There was no significant difference in terms of systolic and diastolic blood pressure, airway pressure, level of $\mathrm{CO}_{2}$ in exhaled air, and oxygen saturation level measured continuously during surgery between the 2 groups of study. 
Table 3. Comparison of Arrhythmia, Oxygen Desaturation, and Laryngospasm Incidence Between ETT and LMA Groups ${ }^{\mathrm{a}}$

\begin{tabular}{|c|c|c|c|c|c|c|c|c|c|}
\hline \multirow[t]{2}{*}{ Variables } & \multicolumn{3}{|c|}{ laryngospasm } & \multicolumn{3}{|c|}{ Oxygen desaturation } & \multicolumn{3}{|c|}{ Arrhythmia } \\
\hline & Yes & No & Pvalue & Yes & No & Pvalue & Yes & No & Pvalue \\
\hline LMA (42) & 0 & $42(100)$ & 0.2 & $3(7.2)$ & $39(92.8)$ & 0.4 & $1(2.3)$ & $39(97.7)$ & 0.4 \\
\hline
\end{tabular}

Abbreviations: ETT,Endotracheal Tube; LMA, Laryngeal Mask Airway. ${ }^{\mathrm{a}}$ Value are expressed as N.(\%).

Table 4. Comparison of Bleeding Level Between ETT and LMA Groups ${ }^{\mathrm{a}}$

\begin{tabular}{lccccc}
\hline \multicolumn{5}{c}{ Bleeding } \\
\hline Variables & Very slow & Slow & Middle & Intense & P value \\
\hline ETT (34) & $6(17)$ & $17(50)$ & $10(30)$ & $1(3)$ & 0.01 \\
LMA (42) & $14(33)$ & $24(57)$ & $4(10)$ & $0(0)$ & \\
\hline $\begin{array}{l}\text { Abbreviations: ETT, Endotracheal Tube; LMA, Laryngeal Mask Airway. } \\
\text { a Value are expressed as N. (\%). }\end{array}$
\end{tabular}

Table 5. Comparison of Apnea and Vomiting Incidence Between ETT and LMA Group $^{\mathrm{a}}$

\begin{tabular}{lccc}
\hline \multirow{2}{*}{ Variables } & \multicolumn{3}{c}{ Vomiting } \\
\cline { 2 - 4 } & Yes & No & Pvalue \\
\hline ETT & $6(18)$ & $28(82)$ & 0.2 \\
LMA & $5(12)$ & $37(88)$ & \\
\hline $\begin{array}{l}\text { Abbreviations: ETT, Endotracheal Tube; LMA, Laryngeal Mask Airway. } \\
\text { a Value are expressed as N. (\%). }\end{array}$
\end{tabular}

\section{Discussion}

In this study, the incidence of post-intubation complications after cochlear implantation surgery was examined in patients aged 2 to 12 years divided into ETT and LMA groups. The appropriate size of laryngeal mask was determined based on the patient's weight $(6,7)$. Since the surgery duration was long (more than 100 minutes) and the patients were children, airway management and its complications were of paramount importance for management of anesthesia. Laryngeal mask airway was used as a substitute of endotracheal tube for reduction of airway complications, including postoperative sore throat. On the other hand, it is mandatory to check the auditory nerve during this type of surgery and therefore muscle relaxants should be avoided $(4,5)$.

There was significant reduction in the level of postoperative sore throat in the laryngeal mask airway group compared to the endotracheal tube group. This pain reduction in the use of LMA is caused by its easier insertion and removal as well as the absence of contact with vocal cords. LMA induces less airway stimulation and trauma (3, $8)$. The incidence of sore throat after using LMA was consistent with the results of similar reports (9-11). However, the incidence of sore throat was higher by using the LMA than
Cobra PLA reported by Brimacombe (12) and Ratajczyk (8).

Trauma during insertion of endotracheal tube, endotracheal tube size, type of cuff, manipulation of airway and surrounding tissues, low airway moisture, and high gas flow rate causes postoperative sore throat as well (3). The other studied complications including intraoperative bleeding, decreased oxygen saturation, apnea, laryngospasm, and nausea after surgery were the same between the two groups. The parameters of systolic and diastolic blood pressure, airway pressure, level of oxygen saturation and $\mathrm{CO}_{2}$ in exhaled air during operation were also the same in both groups.

In a study done by Sierpina and his colleagues in 2012 on patients undergoing adenotonsillectomy surgery, the use of tracheal tube and LMA in children was compared and the incidence of complications such as sore throat, bleeding, coughing, and nausea were same in both groups after surgery (4). In 1994, the postoperative sore throat caused by LMA and ETT was compared on 112 children undergoing minor peripheral surgery. The incidence of sore throat was the same in both groups (3).

\subsection{Conclusions}

The use of laryngeal mask for airway management in cochlear implant surgeries in children can be safe with fewer post-intubation complications than the trachea tube. LMA use in other long surgeries and other positions in children is suggested.

\section{References}

1. Kouni SN, Giannopoulos S, Ziavra N, Koutsojannis C. Brainstem auditory evoked potentials with the use of acoustic clicks and complex verbal sounds in young adults with learning disabilities. Am J Otolaryngol. 2013;34(6):646-51. doi: 10.1016/j.amjoto.2013.07.004. [PubMed: 23953938].

2. Eftekharian A, Amizadeh M, Mottaghi K, Safari F, Mahani MH, Ranjbar LA, et al. Effect of depth of general anesthesia on the threshold of electrically evoked compound action potential in cochlear implantation. Eur Arch Otorhinolaryngol. 2015;272(10):2697-701. doi:10.1007/s00405014-3231-z. [PubMed: 25145642].

3. Splinter WM, Smallman B, Rhine EJ, Komocar L. Postoperative sore throat in children and the laryngeal mask airway. Can J Anaesth. 1994;41(11):1081-3. doi: 10.1007/BF03015658. [PubMed: 7828256]. 
4. Sierpina DI, Chaudhary H, Walner DL, Villines D, Schneider K, Lowenthal $\mathrm{M}$, et al. Laryngeal mask airway versus endotracheal tube in pediatric adenotonsillectomy. Laryngoscope. 2012;122(2):429-35. doi: 10.1002/lary.22458. [PubMed: 22252780].

5. Taheri A, Hajimohamadi F, Soltanghoraee H, Moin A. Complications of using laryngeal mask airway during anaesthesia in patients undergoing major ear surgery. Acta Otorhinolaryngol Ital. 2009;29(3):151-5. [PubMed: 20140161].

6. McHardy FE, Chung F. Postoperative sore throat: cause, prevention and treatment. Anaesthesia. 1999;54(5):444-53. doi: 10.1046/j.13652044.1999.00780.x. [PubMed:10995141].

7. Asai T, Brimacombe J. Review article: cuff volume and size selection with the laryngeal mask. Anaesthesia. 2000;55(12):1179-84. doi: 10.1046/j.1365-2044.2000.01624.x. [PubMed:11121927].

8. Ratajczyk P, Malachowska B, Gaszynska E, Gaszynski T. A randomised comparison between Cobra PLA and classic laryngeal mask airway and laryngeal tube during mechanical ventilation for general anaesthesia. Anaesthesiol Intensive Ther. 2013;45(1):20-4. doi:
10.5603/AIT.2013.0004. [PubMed: 23572303].

9. Dingley J, Whitehead MJ, Wareham K. A comparative study of the incidence of sore throat with the laryngeal mask airway. Anaesthesia 1994;49(3):251-4. [PubMed: 8147523].

10. Turan A, Kaya G, Koyuncu O, Karamanlioglu B, Pamukcu Z. Comparison of the laryngeal mask (LMA) and laryngeal tube (LT) with the new perilaryngeal airway (CobraPLA) in short surgical procedures. Eur J Anaesthesiol. 2006;23(3):234-8. doi: 10.1017/S0265021505002243. [PubMed: 16430795].

11. Wakeling HG, Butler PJ, Baxter PJ. The laryngeal mask airway: a comparison between two insertion techniques. Anesth Analg. 1997;85(3):687-90. doi: 10.1097/00000539-199709000-00037. [PubMed: 9296432].

12. Brimacombe J, Holyoake L, Keller C, Brimacombe N, Scully M, Barry J, et al. Pharyngolaryngeal, neck, and jaw discomfort after anesthesia with the face mask and laryngeal mask airway at high and low cuff volumes in males and females. Anesthesiology. 2000;93(1):26-31. doi: 10.1097/00000542-200007000-00009. [PubMed: 10861142]. 